\title{
Awareness about FDA announcement on voluntary recall of ranitidine among physicians and pharmacists in and around Chennai, India: a cross-sectional study
}

\author{
Rukaiah Fatma Begam, Yamuna Ravikumar and Ramaiyan Velmurugan * (D)
}

\begin{abstract}
Background: Ranitidine is a histamine-2 $(\mathrm{H} 2)$ blocker, which decreases the amount of acid created by the stomach. In September 2019, the drug was recalled due to impurities N-nitrosodimethylamine (NDMA) by the Food and Drug Administration (FDA), European Medicines Agency (EMA), and Health Canada. NDMA is a carcinogen based on results from laboratory tests. The objective of the study is to assess the awareness among the physicians and pharmacists in and around Chennai about the ranitidine recall notification and its related issues. A descriptive, cross-sectional study was carried out where a questionnaire was administered on 198 physicians and 113 pharmacists who were enrolled in the study. Awareness, knowledge, and issues related to recall notification were recorded from the participants.

Results: Results showed that only $75 \%$ of the study participants were aware of the notification and the issues related, with significantly more participants from the urban area compared with the rural area. When the notification was known by many, the reasons pertaining to the notification were not known.

Conclusion: Overall, the awareness assessed among physicians and pharmacists was not satisfactory. Physicians and pharmacists are the most responsible healthcare providers and to be updated with every notification on medication published by regulatory bodies.
\end{abstract}

Keywords: Ranitidine, NDMA, Recall notification, Awareness, Physicians, Pharmacists

\section{Background}

Ranitidine is a histamine H2-receptor antagonist which differs in chemical structure from both histamine and cimetidine $[1,2]$. It is generally used in the treatment of ulcer disease, Zollinger-Ellison syndrome, and hyper gastric secretion [3-5]. Ranitidine is very much selective that high concentrations do not affect $\beta$ adrenoreceptor, histamine $\mathrm{H} 1$, and muscarinic receptor-mediated responses [6,7]. It is effective by both parenteral and oral routes of administration [8-10].

Ranitidine medicines with some brand names Zantac were investigated for nitrosamine impurity called N-

\footnotetext{
* Correspondence: ramaiyan.dr@gmail.com

School of Pharmaceutical Sciences, Vels Institute of Science Technology and Advanced Studies, Chennai 600117, India
}

nitrosodimethylamine (NDMA) at low levels by the United States Food and Drug Administration (USFDA). NDMA is defined to be a human carcinogen based on laboratory results. NDMA is an environmental contaminant and is found in water and foods, including meats, dairy products, and vegetables [11].

The NDMA and other nitrosamine impurities in blood pressure and heart failure medicine angiotensin II receptor blockers (ARBs) were under investigation by FDA quite long back. For any medicines, the impurities are supposed to be more number of times by FDA. When the agency identifies a problem, it takes appropriate action quickly to protect patients. The impact of low levels of NDMA in ranitidine is under evaluation whether it would pose any risk to patients and the same will be published by FDA once 
available. Patients should trust a medicine for its safety and efficacy. However, NDMA may cause harm only in larger amounts, and the levels the FDA is finding in ranitidine from preliminary tests barely exceed amounts you might expect to find in common foods [12].

The FDA in collaboration with other international drug regulators and various industrial partners is assigned in determining the source of this impurity in ranitidine. The agency is identifying the levels of NDMA in ranitidine and trying to evaluate the possible risks to the patients. Based on the results that are to arrive, the FDA will initiate necessary measures. The agency will publish the information once it becomes available. However, the FDA does not call for individuals to stop taking ranitidine at this time. $\mathrm{Pa}$ tients who wish to discontinue the prescription of ranitidine after getting known the recall of ranitidine, however, should talk to their healthcare providers about the other treatment options. People who take over-the-counter (OTC) ranitidine may go with other approved OTC medicines for their conditions as per the need as there are multiple approved drugs available in the market for the same indications as ranitidine [13].

It is the responsibility of both the consumers and healthcare providers to report for any adverse reactions with ranitidine (if encountered) to the FDA's MedWatch program to help the agency better understand the scope of the problem and requested to report online at www.fda.gov/ medwatch/report.htm. The FDA, an agency within the US Department of Health and Human Services, protects the public health by assuring the safety, effectiveness, and security of human and veterinary drugs, vaccines, and other biological products for human use, and medical devices. It is again the responsibility of the agency to assure the safety and security of the nation's food supply, cosmetics, dietary supplements, and products that give off electronic radiation, and for regulating tobacco products [11-13].

USFDA press announcement on alerting patients and healthcare providers of NDMA found in ranitidine was published on 09/13/2019. A kind of oral interview made around the medical professionals over this time to get to know their stand on the recall notification indicated that few had inadequate knowledge and awareness on the same and were not confident enough about the issues related to ranitidine withdrawal. Upon the interview made with the pharmacist, it was observed that there was a lack of a clear understanding of the reason for the withdrawal. Given that physicians and pharmacists are trained as medication experts who may provide direct patient care, it seems counter-intuitive that they are not perceived as essential in the withdrawal notification of ranitidine by USFDA. Patients often look to healthcare professionals as sources of medicine information [14]. Drug recalls are conducted for seriously defective products that pose health risks to patients voluntarily by manufacturers or by mandate of regulatory authorities [15]. A recall acts like an alarm that makes the company realize that it is time to take corrective action by reviewing and making changes in the required areas [16]. On 5 July 2018, the EMA reviewed medicines containing valsartan following detection of NDMA in valsartan from Zhejiang Huahai Pharmaceutical Co Ltd, Linhai, China. Since the batches manufactured from this valsartan-active substance have been administered to many patients, the agency further issued a recall notification [17]. Similar to ranitidine recall notification, Nostrum Laboratories, Inc. expands voluntary nationwide recall of metformin $\mathrm{HCl}$ extended-release tablets, USP $750 \mathrm{mg}$, due to NDMA content above the acceptable daily intake limit $[18,19]$. The FDA published the recall notification on ranitidine medicines over potential cancer-causing impurity [20]. FDA also recommended to discard all ranitidine medications [21]. Hence, it is mandatory that physicians and pharmacists should be aware of the issues related to ranitidine. In this study, we assessed the awareness about FDA announcement on voluntary recall of ranitidine and the issues related among physicians and pharmacists in and around Chennai, India.

\section{Methods}

\section{Study design}

A descriptive, cross-sectional study was carried out from October to December 2019 among physicians and pharmacists working in hospitals in and around Chennai. Due to the nature of the nurses' training and their current roles and responsibilities, nurses were excluded from the study. The study was carried out with the approval of the Institutional Ethics Committee, School of Pharmaceutical Sciences, Vels Institute of Science Technology and Advanced Studies, Chennai, India (VISTAS - SPS/IEC/V/2019/01).

\section{Sample size}

The sample size was calculated using PS-Power and sample size calculator. Considering alpha error at 0.05 and $80 \%$ power of the study (1- $\beta$ ) with an appropriate $8.5 \%$ differences and standard deviation of 0.05 using 1:1 ratio of the independent sample t-test.

$$
\begin{gathered}
\text { Sample size }=\frac{\left(Z_{1-\alpha / 2^{2} P(1-p)}\right)}{(d)^{2}} \\
=\frac{(1.96)^{2} \times 0.314(1-0.314)}{(0.05)^{2}} \\
=311 \text { subjects }
\end{gathered}
$$

\section{Study tool}

The study tool was a questionnaire to assess the awareness about FDA announcement on voluntary recall of 
ranitidine and the issues related. The nature of the questionnaire is that assessing the awareness about the FDA announcement on the manufacturers to withdraw all prescription and over-the-counter (OTC) ranitidine drugs from the market immediately, as there is an ongoing investigation of a contaminant known as $\mathrm{N}$ nitrosodimethylamine (NDMA) in ranitidine medications. Tailored questionnaires for physicians and pharmacists that are included in assessing the awareness of FDA recall notification on ranitidine and much more on the nature of the impurity were reviewed and agreed by a panel of 6 experts with clinical, pharmacy, and academic backgrounds. A preliminary interview was conducted with 10 physicians and 10 pharmacists across two hospitals to test the content and face validity of the questionnaire. Minor format changes were made to improve the clarity of some questions without changing their essence. Data obtained from the preliminary interview with 10 physicians and 10 pharmacists were excluded from the study results. The study population included a total of 198 physicians and 113 pharmacists. Each participant was asked to complete the questionnaire (given as a supplementary file). The demographic data such as age, gender, occupation, level of education, and locality are recorded. Each individual was asked to answer the questions on his/her awareness about the withdrawal notification on ranitidine and the reasons regarding the withdrawal. Only the investigators had access to the data collected. The data management and statistical analysis were carried out using the computer software Graphpad Prism. Comparisons between categorical variables were performed using the chi-squared test. For all statistical analyses, the level of significance was set at $p<0.05$.

\section{Results}

\section{Demographics}

The questionnaire was administered to a total of 311 participants (198 physicians and 113 pharmacists) and their responses were recorded. The study sample consisted of 64\% physicians (198/311) and 36\% pharmacists (113/311). The sociodemographical characteristics of the participants are presented in Table 1 . There were significantly more female pharmacists compared with physicians $(\mathrm{n}=47 / 113 ; 41 \%$ vs $\mathrm{n}=72 / 19 ; 36 \% ; p<0.001)$. The overall median age was 45 years, ranging between 30 and 60 years, and was not significantly different between physicians and pharmacists $(p=0.482)$. Localitywise, $\mathrm{n}=78 / 198(37 \%)$ physicians were from the rural area and $n=120 / 198$ (63\%) physicians were from the urban area. With respect to pharmacists, $\mathrm{n}=32 / 113$ (28\%) were from the rural area and $\mathrm{n}=81 / 113(72 \%)$ were from the urban area. More than $50 \%$ of both the physicians and pharmacists had more than 10 years of experience. The study participant flow chart is given in Fig. 1.

\section{Awareness about FDA announcement on voluntary recall of ranitidine and the related issues}

The awareness recorded on various questions administered to the participants related to the ranitidine recall notification is summarized in Table 2. Most participants ( $\mathrm{n}=230 / 311 ; 74 \%)$ reported being familiar with the ranitidine recall notification from FDA. Seventy-six percent of physicians and $71 \%$ of pharmacists were well aware of the ranitidine recall notification. The same reported were aware of the impurity NDMA identified. Ninety-five percent of physicians and $87 \%$ of pharmacists were aware that NDMA is classified as a probable

Table 1 The detailed demographic characteristics of the study population

\begin{tabular}{|c|c|c|c|c|}
\hline Characteristic & $\begin{array}{l}\text { All }(n=311) \\
n(\%)\end{array}$ & $\begin{array}{l}\text { Physician }(\mathrm{n}=198) \\
\mathrm{n}(\%)\end{array}$ & $\begin{array}{l}\text { Pharmacist }(n=113) \\
n(\%)\end{array}$ & $p$ value \\
\hline Gender* & & & & $<0.05$ \\
\hline Male & $180(58)$ & $126(64)$ & $66(59)$ & \\
\hline Female & $131(42)$ & $72(36)$ & $47(41)$ & \\
\hline Age (years)* & & & & 0.482 \\
\hline $31-40$ & $107(34)$ & $58(29)$ & $28(25)$ & \\
\hline $41-50$ & $124(48)$ & $103(52)$ & $66(58)$ & \\
\hline $51-60$ & $80(26)$ & $37(19)$ & $19(17)$ & \\
\hline Locality* & & & & $<0.001$ \\
\hline Rural & $88(28)$ & $78(37)$ & $32(28)$ & \\
\hline Urban & $223(72)$ & $120(63)$ & $81(72)$ & \\
\hline Year of experience* & & & & 0.532 \\
\hline$<10$ & $118(38)$ & $63(32)$ & $33(29)$ & \\
\hline$>10$ & $183(62)$ & $135(68)$ & $80(71)$ & \\
\hline
\end{tabular}




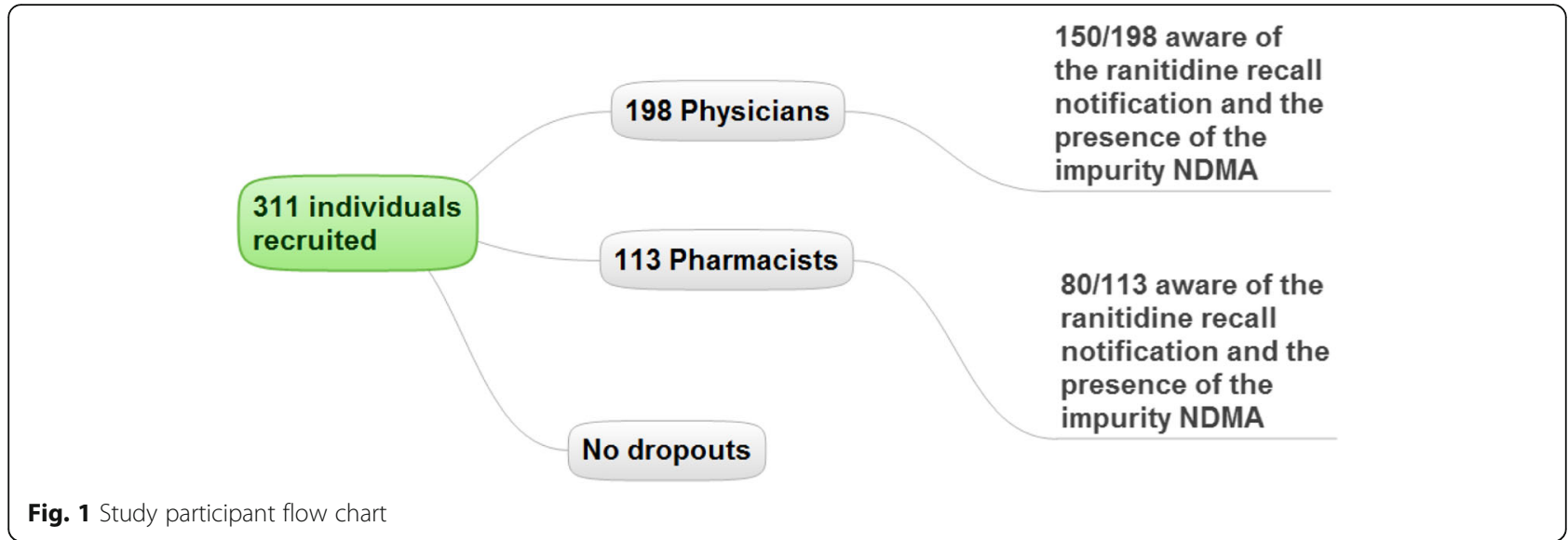

human carcinogen (a substance that could cause cancer).

When it comes to the source of impurity, only $14 \%$ of the physicians were aware of it whereas $90 \%$ of the pharmacists were aware of the source of the impurity identified and this might probably be due to the core area they are working in.

When participants were interviewed regarding the maximum daily intake and currently agreed threshold of NMDA, less than $5 \%$ of the physicians and pharmacists only were aware of the currently agreed threshold of the impurity and the maximum daily intake of the same. However, $58 \%$ of the pharmacists and $5 \%$ of the physicians were able to calculate the limit of the impurity in parts per million.

The call back impact on Indian manufacturers was surveyed among the participants where $78 \%$ of the pharmacists were aware of it and only $13 \%$ of the physicians were aware as they were practitioners. This is again as discussed in the previous interview, much of the pharmacists were aware as they in the core area of pharmaceutical manufacturing.

When the participants were interviewed to get to know whether the impurity in ranitidine products poses any immediate health risks, $100 \%$ of physicians and $90 \%$ of pharmacists were aware it may pose any health risks

Table 2 Awareness about FDA announcement on voluntary recall of ranitidine and the issues related

\begin{tabular}{|c|c|c|c|c|c|}
\hline Awareness & Response & $\begin{array}{l}\text { All }(n=311) \\
n(\%)\end{array}$ & $\begin{array}{l}\text { Physician } \\
(\mathrm{n}=198) \\
\mathrm{n}(\%)\end{array}$ & $\begin{array}{l}\text { Pharmacist } \\
(\mathrm{n}=113) \\
n(\%)\end{array}$ & $p$ value \\
\hline \multirow[t]{2}{*}{ Are you aware of FDA recall notification on ranitidine? } & Yes & $230(74)$ & $150(76)$ & $80(71)$ & 0.05 \\
\hline & No & $81(26)$ & $48(24)$ & $33(29)$ & \\
\hline \multirow[t]{2}{*}{ What is the impurity identified? } & Yes & $230(74)$ & $150(76)$ & $80(71)$ & 0.05 \\
\hline & No & $81(26)$ & $48(24)$ & $33(29)$ & \\
\hline \multirow[t]{2}{*}{ What is the ADR caused by the impurity? } & Yes & $286(92)$ & $188(95)$ & 98 (87) & 0.05 \\
\hline & No & $25(8)$ & $10(5)$ & $15(13)$ & \\
\hline \multirow[t]{2}{*}{ What is the source of the impurity? } & Yes & $40(13)$ & $28(14)$ & $101(90)$ & $<0.001$ \\
\hline & No & $271(87)$ & $170(86)$ & $12(10)$ & \\
\hline \multirow[t]{2}{*}{ What is the maximum daily intake of the impurity identified? } & Yes & $18(6)$ & $11(5)$ & $7(6)$ & 0.992 \\
\hline & No & $293(94)$ & $187(96)$ & $106(94)$ & \\
\hline \multirow[t]{2}{*}{ What is the currently agreed threshold for the impurity in ranitidine? } & Yes & $12(4)$ & $08(4)$ & 04 (3) & 0.992 \\
\hline & No & $299(96)$ & $190(96)$ & $109(97)$ & \\
\hline \multirow[t]{2}{*}{ How do you calculate the limit of the impurity in parts per million? } & Yes & $76(24)$ & $11(5)$ & $65(58)$ & $<0.001$ \\
\hline & No & $235(76)$ & $187(95)$ & $48(42)$ & \\
\hline \multirow[t]{2}{*}{ Do you know the call back impact on Indian manufacturers? } & Yes & $114(37)$ & $26(13)$ & $88(78)$ & $<0.001$ \\
\hline & No & $197(63)$ & $172(87)$ & $25(22)$ & \\
\hline \multirow[t]{2}{*}{ Does the impurity in ranitidine products pose any immediate health risks? } & Yes & $300(96)$ & $198(100)$ & $102(90)$ & 0.05 \\
\hline & No & $11(4)$ & 0 & $11(10)$ & \\
\hline
\end{tabular}


only after exposure to high doses over a long period of time.

\section{Discussion}

In the world of regulatory sciences, such incidents are common and observed by many drug substance manufacturers during routine and stress testing and even after marketing of the product during real-time stability and postmarketing analysis as it happened recently with valsartan, an orally active antihypertensive drug developed in the 1990s and is a selective angiotensin II receptor blocker (ARB) which relaxes the blood vessels and thus reduces blood pressure. In 2018, USFDA published a recall notification on valsartan for the detection of impurities in the active substance [22].

Any change in the manufacturing process, material, or intermediates; control of critical steps impurities; specification; and analytical procedure is to be informed to marketing authorization holders, who are legally bound to inform the same to their concerned regulatory body $[23,24]$. This regulatory gap was evident in this case since the manufacturers of the Active Pharmaceutical Ingredients (API) did not inform existing marketing authorization holders regarding the change in the manufacturing process and hence the problem could not be identified in the early stages.

National regulatory bodies take immediate steps to ensure the provision of correct information to healthcare providers and that is to be adhered by the healthcare providers and the case here is all about the medication. In the context of patient safety initiatives and in line with the USFDA recall notification on ranitidine for the presence of an impurity NMDA identified, this study provides data on the current state of awareness on the recall notification among the physicians and pharmacists in and around Chennai, India. This is the first time study to assess the awareness on the FDA recall notification which was not recorded previously.

Overall, participants in this study are strong where they are supposed to be which is in line with recent findings. When it comes to clinical practice and therapeutics, physicians are well aware of the related questions they were interviewed and, on the other hand, with questions related to manufacturing and posology, pharmacists were well aware of it.

In line with data obtained from the rural and urban locality, our findings indicate that the majority of participants who were not familiar with the ranitidine recall notification and the related issues were from the rural area. They claimed that urbanization and technology that they lack was the reason for their unawareness. Few physicians and pharmacists had different perspectives regarding the ranitidine recall notification and were not clear on which profession was responsible for the same.
When it comes to the source of impurity, it is known that these impurities can be formed during the production under certain conditions and when certain solvents, reagents, and other raw materials are used. In addition, it is possible that impurities were present in some ranitidine because manufacturers had inadvertently used contaminated equipment or reagents in the manufacturing process. Companies must take measures to avoid the presence of these impurities and carry out rigorous testing of their products.

Ranitidine medications are available in two different strengths as $150 \mathrm{mg}$ and $300 \mathrm{mg}$ tablets. The maximum daily intake of NDMA is $96.0 \mathrm{ng}$. The limits are based on the maximum daily intake for each impurity derived from animal studies. Dividing these by the maximum daily dose for each active substance gives the limit in parts per million. For the available strengths $150 \mathrm{mg}$ and $300 \mathrm{mg}$, the limits measured were $0.64 \mathrm{ppm}$ and 0.32 ppm (Table 3) respectively which exceeds $0.16 \mathrm{ppm}$, the currently agreed threshold for NDMA in ranitidine hydrochloride [25].

Glaxo Smithkline Pharmaceuticals Ltd (GSK), Mumbai, India, is the largest manufacturer of ranitidine (Zantac 150/300 mg tablets). Based on the information provided by the regulatory authorities about the detection of NDMA, as a precautionary action, GSK and other Indian manufacturers have made the decision to initiate a voluntary recall of Zantac tablets manufactured in India.

It is important to know that the NDMA in ranitidine products does not pose any immediate health risks. Although classified as a probable carcinogen, NDMA may cause cancer only after exposure to high doses over a long period of time. Induction of tumors in rats after chronic exposure to low doses of NMDA is recorded [26].

On the whole, approximately $75 \%$ of the study participants only were aware of the notification and the issues related. Perhaps, as the impurity does not pose any serious adverse effects very immediately with few doses, the current scenario on awareness about the recall notification studied may not be having an impact. However, such a thing to be imagined for an impurity that causes very serious events even upon one single dose, being healthcare providers, it is the role of the physicians and the pharmacists to update themselves and to educate fellow workers. Reallocating tasks and responsibilities to

Table 3 Calculating maximum daily intake and parts per million of NMDA

\begin{tabular}{lll}
\hline NMDA & & \\
\hline $\begin{array}{l}\text { Active substance (max daily } \\
\text { dose) }\end{array}$ & $\begin{array}{l}\text { Maximum daily intake } \\
(\mathbf{n g})\end{array}$ & $\begin{array}{l}\text { Limit } \\
(\mathbf{p p m})\end{array}$ \\
\hline 150 & 96.0 & 0.64 \\
300 & 96.0 & 0.32 \\
\hline
\end{tabular}


other regulated healthcare professionals besides physicians and pharmacists may be the most critically needed change in the implementation process. National regulatory bodies should ensure that the healthcare providers are aware of the information published from the department, which in this case seemed to be missing in various countries.

\section{Conclusion}

A drug recall is the most effective way to protect the public from a defective or potentially harmful product. FDA's role in a recall is to oversee a company's strategy, assess the adequacy of the recall, and classify the recall. And of course, it will be a public notification when a product has been widely distributed or poses a serious health hazard. In such cases, patients may learn their medicine's best course of action on their health, including the possibility of returning the product to the store in which they purchased it from their healthcare professional or pharmacist. In that case, the healthcare providers should be updated with the international information as the safety of the patient is of utmost importance.

\section{Abbreviations}

H2: Histamine-2; NDMA: N-Nitrosodimethylamine; USFDA: United States Food and Drug Administration; EMA: European Medicines Agency; ARBs: Angiotensin II receptor blockers; OTC: Over the counter; GSK: Glaxo Smithkline Pharmaceuticals Ltd; API: Active Pharmaceutical Ingredients

\section{Supplementary Information}

The online version contains supplementary material available at https://doi. org/10.1186/s43094-021-00267-7.

Additional file 1. Questionnaire.

\section{Acknowledgements}

The authors wish to thank the Institutional Ethics Committee, Vels Institute of Science Technology and Advanced Studies, Chennai, India, for approving the study and the Faculty of Pharmaceutical Sciences for carrying out this research study and to all the respondents who participated in the study.

\section{Authors' contributions}

RV conceptualized the project and gave technical inputs in conducting the study and approved the manuscript. RFB performed the study and prepared the manuscript. YR gave technical inputs in conducting the study. All authors have read and approved the final manuscript.

\section{Funding}

No funding was received through any funding agencies towards carrying this research work

\section{Availability of data and materials}

Data and material are available upon request.

\section{Declarations}

Ethics approval and consent to participate

The study protocol was reviewed and approved by the Institutional Ethics Committee, School of Pharmaceutical Sciences, Vels Institute of Science Technology and Advanced Studies, Chennai, India 600117. Written informed consent has been obtained from the study participants explaining to them that the data obtained from each of them will be published.

\section{Consent for publication}

Consent was taken from the study participants informing them that the obtained data will be published.

\section{Competing interests}

The authors declare that they have no competing interests.

Received: 23 April 2020 Accepted: 18 May 2021

Published online: 28 May 2021

\section{References}

1. Dawson J, Richards DA, Stables R, Dixon GT, Cockel R (1983) Ranitidine-pharmacology and clinical use. J Clin Hosp Pharm 8(1):1-13. https://doi. org/10.1111/j.1365-2710.1983.tb00892.x

2. Mitchard M, Harris A, Mullinger BM (1987) Ranitidine drug interactions-a literature review. Pharmacol Ther 32(3):293-325. https://doi.org/10.1016/01 63-7258(87)90078-7

3. Strum WB (1983) Ranitidine. JAMA 250(14):1894-1896. https://doi.org/10.1 001/jama.1983.03340140064032

4. Chopra D, Arora P, Khan S, Dwivedi S (2014) Anaphylaxis following intravenous ranitidine: a rare adverse reaction of a common drug. Indian J Pharm 46(2):234-236. https://doi.org/10.4103/0253-7613.129334

5. Colin A, Helman MD, Leonard Ou Tim MD (1983) Pharmacology and clinical efficacy of ranitidine, a new H2-receptor antagonist. Pharmacother 3(4):185192. https://doi.org/10.1002/j.1875-9114.1983.tb03248.x

6. Daly MJ, Stables R (1980) In vitro actions of ranitidine, a new histamine H2receptor antagonist. Agents Actions 10(1-2):190-191. https://doi.org/10.1 007/BF02024210

7. Brogden RN, Carmine AA, Heel RC, Speight TM, Avery GS (1982) Ranitidine: a review of its pharmacology and therapeutic use in peptic ulcer disease and other allied diseases. Drugs 24(4):267-303. https://doi.org/10.2165/ 00003495-198224040-00002

8. Aouam K, Bouida W, Ben Fredj N, Chaabane A, Boubaker H, Boukef R (2011) Severe ranitidine-induced anaphylaxis: a case report and literature review. J Clin Pharm Ther 37(4):494-496. https://doi.org/10.1111/j.1365-2710.2011. 01320.x

9. Woodings EP, Dixon GT, Harrison C, Carey P, Richards DA (1980) Ranitidine-a new H2-receptor antagonist. Gut 21(3):187-191. https://doi.org/10.1136/ gut.21.3.187

10. McNeil JJ, Mihaly GW, Anderson A, Marshall AW, Smallwood RA, Louis WJ (1981) Pharmacokinetics of the $\mathrm{H} 2$-receptor antagonist ranitidine in man. $\mathrm{Br}$ J Clin Pharmacol 12(3):411-415. https://doi.org/10.1111/j.1365-2125.1981. tb01236.x

11. U.S. Food and Drug Administration (2020) FDA updates and press announcements on NDMA in Zantac (ranitidine) https://www.fda.gov/ drugs/drug-safety-and-availability/fda-updates-and-press-announcementsndma-zantac-ranitidine. Accessed 16 Apr 2020

12. U.S. Food and Drug Administration (2020) FDA updates and press announcements on alerting patient and health care professionals on NMDA in ranitidine. https://www.fda.gov/news-events/press-announcements/sta tement-alerting-patients-and-health-care-professionals-ndma-found-sa mples-ranitidine. Accessed 18 Apr 2020.

13. U.S. Food and Drug Administration (2020) FDA updates and press announcements on voluntary recall of ranitidine capsules. https://www.fda. gov/news-events/press-announcements/fda-announces-voluntary-recall-sa ndoz-ranitidine-capsules-following-detection-impurity. Accessed $14 \mathrm{Apr}$ 2020

14. Leary A, Usher C, Lynch M, Hall M, Hemeryk L, Spillane S (2015) Generic medicines and generic substitution: contrasting perspectives of stakeholders in Ireland. BMC Res Notes 8(1):790. https://doi.org/10.1186/ s13104-015-1764-x

15. Venkatesh MP, Bigoniya D, Pramod Kumar TM (2017) Pharmaceutical product recall procedures in India, South Africa and China. Int J Pharm Sci Rev Res 46:98-104

16. Richa S (2013) Global perspective and issues relating to product recall. IOSR J Bus Manag 12:22-26 
17. Muhammad JF, Muhammad HT, Obaidullah M, Tahir MK (2019) Valsartan recall: global regulatory overview and future challenges. Therapeutic Adv Drug Safety 10:1-4

18. U.S. Food and Drug Administration (2020) FDA updates and press announcements on Nostrum Laboratories, Inc. expands voluntary nationwide recall of metformin $\mathrm{HCl}$ extended release tablets, USP $750 \mathrm{mg}$ due to $\mathrm{N}$-nitrosodimethylamine (NDMA) content above the acceptable daily intake (ADI) limit. https://www.fda.gov/safety/recalls-market-withdrawals-sa fety-alerts/nostrum-laboratories-inc-expands-voluntary-nationwide-recallmetformin-hcl-extended-release-tablets. Accessed 4 Jan 2021

19. Ajith Kumar PV, Deepa M (2020) Metformin and nitrosamine impurities. Int J Res Med Sci 8:3778-3784

20. USFDA (2019) FDA recalls ranitidine medicines over potential cancer causing impurity. Br Med J 367:15832

21. USFDA (2020) All ranitidine should be discarded, says US drug agency. Br Med J 369. https://doi.org/10.1136/bmj.m1390

22. U.S. Food and Drug Administration (2019) FDA updates and press announcements on FDA updates and press announcements on angiotensin II receptor blocker (ARB) recalls (valsartan, losartan, and irbesartan). https:// www.fda.gov/drugs/drug-safety-and-availability/fda-updates-and-press-a nnouncements-angiotensin-ii-receptor-blocker-arb-recalls-valsartan-losartan. Accessed 13 Nov 2019

23. Molzon J (2003) The common technical document: the changing face of the new drug application. Nat Rev Drug Discov 2(1):71-74. https://doi.org/1 $0.1038 /$ nrd990

24. Molzon JA, Giaquinto A, Lindstrom L, Tominaga T, Ward M, Doerr P (2011) The value and benefits of the international conference on harmonisation to drug regulatory authorities: advancing harmonization for better public health. Clin Pharmacol Ther 89(4):503-512. https://doi.org/10.1038/clpt.2 011.10

25. U.S. Food and Drug Administration (2019) FDA updates and press announcements on liquid chromatography-tandem mass spectrometry (LCMS/MS) method for the determination of NDMA in ranitidine drug substance and solid dosage drug product. https://www.fda.gov/media/131 868/download. Accessed 17 Oct 2019

26. Richard P, Richard G, Paul B, Paul G (1991) Dose and time relationships for tumor induction in the liver and esophagus of 4080 inbred rats by chronic ingestion of A-nitrosodiethylamine or W-nitrosodimethylamine. Cancer Res 51:6452-6469 http://cancerres.aacrjournals.org/content/51/23_Part_2/6452

\section{Publisher's Note}

Springer Nature remains neutral with regard to jurisdictional claims in published maps and institutional affiliations.

\section{Submit your manuscript to a SpringerOpen ${ }^{\circ}$ journal and benefit from:}

- Convenient online submission

- Rigorous peer review

- Open access: articles freely available online

- High visibility within the field

- Retaining the copyright to your article

Submit your next manuscript at $\boldsymbol{\nabla}$ springeropen.com 